\title{
Does 'local' matter in restaurant choice? Results of a discrete choice experiment targeting German and Italian consumers
}

\author{
Caterina Contini ${ }^{*}$ (D), Caterina Romano, Fabio Boncinelli, Gabriele Scozzafava and Leonardo Casini
}

\author{
* Correspondence: \\ caterina.contini@unifi.it \\ Dipartimento di Gestione dei \\ Sistemi Agrari, Alimentari e Forestali, \\ University of Florence, Piazzale delle \\ Cascine, 18, 50144 Florence, Italy
}

\begin{abstract}
Consumer preferences about locally grown foods have been studied principally as they concern meals consumed in the home, while knowledge about consumptions outside the home is still fragmented. Studying the relationship between local foods and out of the home consumptions instead proves particularly interesting, considering the growth of eating out habits. In this scenario, our paper intends to verify whether using products of local origin in restaurants can represent an element capable of influencing consumer preferences positively. The analysis was developed by means of a choice experiment between alternatives that differ in certification of origin, process certification, price and the main characteristics of the restaurant. The survey was conducted on a representative sample of Italian (500) and German (500) consumers. Applying Latent Class Modelling has enabled us to segment the market and profile the segments. Profiling was performed considering the sociodemographic characteristics, the choice motivations not expressly inserted in the choice experiment and the Schwartz value system. The results show not only a marked heterogeneity of preferences but also a consistent consumer segment willing to pay a relevant premium price for meals made from a prevalence of products certified as being of local origin. This segment, labelled 'locavores', appears across both countries, despite differing gastronomic traditions. Locavores are mainly young people who prioritise self-enhancement, stimulation and conservation in the sense of respect for traditions and being members of their communities. The 'Discussions and conclusions' section handles the principal implications from the viewpoint of the decisions of restaurant owners, as well as from that of farmers.
\end{abstract}

Keywords: Local foods, Restaurant choice, Consumer segmentation, Latent class, Consumer profiling

\section{Background}

As of late, we have been witnessing a return to the use of local foods in consumption habits, as a consequence of an evolution of the food and cultural system (Bean and Sharp 2011; Rausser et al. 2015). While before globalisation, consuming local foods indeed represented the custom, because foods were plausibly local for the most part, today this orientation assumes the connotations of the individual's conscious and weighted choice.

The reasons for the renewed interest in the local origin of foods can be attributed to the new sense of the local food system, which expands its distinctive features to 
embrace issues involving the environment, health and the sustainability of food consumptions (Feenstra 1997). In this context, the different inclinations of consumers towards the environment, health and food safety have led to identify the nearness to the site of production as a quality cue, which thereby contributes to increasing the demand for local food (Roininen et al. 2006). Moreover, this phenomenon has also benefited from the resolution of several issues that in the past represented a barrier to the consumption of local foods, such as the scarce availability of products, tied to limits in the distribution channels (Frash et al. 2015).

The literature has investigated consumer preferences with respect to the 'local' attribute of food, mainly concentrating on the choices of the meal to consume at home. In particular, studies have pointed out the characteristics the consumer associates with product quality (Schneider and Francis 2005; Dunne et al. 2011). Previous results show that the value of these foods can be associated not only with taste and freshness (Keeling-Bond et al. 2009; Gracia et al. 2012; Menapace and Raffaelli 2013) but also with safety, nutritional aspects, environmental sustainability (Weber and Matthews 2008, Erraach et al. 2014; Goetzke et al. 2014), support to communities and social responsibility (Darby et al. 2008; Martinez 2010; Frash et al. 2015). Apart from these cases, only a few studies have analysed consumer choices of food produced using local ingredients for away-from-home meals (Frash et al. 2015; Vieregge et al. 2007), and to date, there have been few studies on consumer preferences with respect to local foods appearing on restaurant menus (Alfnes and Sharma 2010; Schubert et al. 2010; Alonso et al. 2013; Campbell and DiPietro 2014; Lillywhite and Simonsen 2014).

In a context of restaurant choice, literature has indeed concentrated on other factors that influence preferences. In their review of food service selection factors important to the consumer, Medeiros and Salay (2013) identify the following as determinant: food type, food quality, service quality, price, location, atmosphere and past experiences both direct and indirect. In particular, studies report that food quality, mainly intended in terms not only of taste but also of the healthiness of foods, is the most important attribute in restaurant choice (Alonso et al. 2013; Frash et al. 2015; Jung et al. 2015).

The issue about price is instead more complex, as price can be considered as a critical factor that limits choice, as well as a quality cue that instead encourages choice (Jung et al. 2015). Previous positive experiences, along with several characteristics of the restaurant, such as its atmosphere and the quality of service constitute further variables that influence consumer preferences, but only after food quality has been determined (Namkung and Jang 2007; Choi and Zhao 2010; Ha and Jang 2010; Ponnam and Balaji 2014). Finally, recent studies have tackled the topic of additional information on the menu (Liu et al. 2012; Thorndike et al. 2012; Feldman et al. 2015; Lu and Gursoy 2016). As far as nutritional indications are concerned, the literature shows that it can increase the consumer's intention to purchase (Liu et al. 2012; Thorndike et al. 2012; Feldman et al. 2015). Likewise, in the ambit of the aspects associated with food safety, $\mathrm{Lu}$ and Gursoy (2016) found a willingness to pay for GMO-free menus.

In this picture, the role of the local origin of raw materials in restaurant choice remains to be further investigated. Schubert et al. (2010) have found the existence of a potential so-called 'green' niche market that also embraces restaurants that serve locally grown foods. Campbell and DiPietro (2014) suggest that consumer response to local food signage is enhanced when farm name and pictures are included. Alfnes and 
Sharma (2010) show that locally grown foods are chosen by a greater number of customers when they are supported by a price signal, or rather, they are sold at a higher price than other food. Signals of the positive role that serving local products can have on consumer preferences are also drawn by Lillywhite and Simonsen (2014) on a sample of 320 consumers. Their study shows that using local ingredients in the preparation of dishes represents the most important choice factor for one fifth of respondents. Vieregge et al. (2007) and Frash et al. (2015) confirm the interest in the local origin of raw materials, revealing that using local food products can improve the image of globally branded restaurants. On the other hand, the results of a study conducted by Alonso et al. (2013) in the south-eastern USA show that the use of local foods on the menu is one of the least influential factors in restaurant choice, even in the case of a region with an important agricultural background and a considerable variety of products.

The analysis of literature points out the limited number of studies conducted on the relationship between local foods and restaurant choice, as well as fragmentation in terms of results. On the other hand, the growing attention consumers show for local products in a context that sees the increasing importance of out of the home consumptions (Casini et al. 2015) implies that understanding the role that the local origin of food can assume in restaurant choice is an important and topical theme, which merits investigation.

The aim of this paper is to examine the relationship between locally grown foods and restaurant choice by analysing the preferences of a representative sample from two countries with very different gastronomical traditions like Italy and Germany. Our paper departs from the hypothesis that the behaviour of consumers is heterogeneous and can be properly interpreted only by means of an analysis that takes account of the diversities. Our contribution to the literature is to shed new light on the diverse sensitivities towards the local origin of products in the restaurant business via a segmentation of consumers, conducted applying the latent class methodology.

In particular, we propose to answer the following research questions: (i) Does a significant market segment exist that is interested in restaurant certification that guarantees the use of local products? (ii) What is the profile of this potential segment?

The paper is structured as follows. In the next section, the study method is illustrated and the methodology based on latent class models is presented. Then, the case study on the choice of a typical restaurant in the two countries is described; the principal results are illustrated, more closely profiling the consumer segments identified. Lastly, we examine the principal implications from the viewpoint of restaurateurs and farmers.

\section{Methods}

\section{Choice experiment: latent class model}

Consumer preferences were analysed by means of discrete choice models (McFadden 1974; Louviere and Woodworth 1983) and, in particular, by using a latent class (LC) model. This model is based on the assumption that the choice behaviour of consumers depends on observable and unobservable heterogeneity that varies with non-detectable factors (Greene and Hensher 2003). It assumes, in particular, that discrete segments of population have different choice behaviours, owing to different preferences. The LC model makes it possible to analyse the heterogeneity of consumers' preferences and, at the same time, to obtain a segmentation into groups of consumers with similar preferences. The LC analysis outperforms 
multivariate clustering techniques, as it is based on a probability model that enables the use of inference on the outcomes. Another advantage of the approach is that it bypasses the problem of choosing linkage rules and dissimilarity measures, the choice of which cannot always be traced back to theoretical economic criteria. Finally, the LC model permits the calculation of statistical indicators, such as Bayesian information criterion (BIC) and Akaike information criterion (AIC) to guide the choice of the number of classes (Magidson and Vermunt 2002; Vermunt and Magidson 2002; Greene and Hensher 2003).

\section{Data analysis and experimental design}

The choice of attributes to define the experiment was made on the basis of the most important attributes of restaurant consumers' choices that emerged in literature (Medeiros and Salay 2013; Alonso et al. 2013; Frash et al. 2015; Jung et al. 2015). Given the purpose of this paper, we have found it advisable to concentrate on the following attributes: average meal price (drinks excluded), quality of service and atmosphere, and food quality, expressed through the certification of the raw materials in terms of production standards and origin (Table 1). Food quality is without a doubt an attribute of fundamental importance in choosing a restaurant; its definition, however, is very complex and subjective. The solution we have adopted in order to include food quality in the choice experiment was to signal it through food certifications, which are objective, easily communicable and utilisable for restaurant choice, not disposing of information tied to direct experience or from relevant others, such as friends and relatives. In order to account for the effects of the more subjective elements, we have specified in the questionnaire that the choice concerned typical restaurants with the same evaluation in the principal food and drink guides and that the alternatives differed only with respect to the attributes considered.

The price levels were chosen considering a price interval that starts from a minimum price of a restaurant meal (drinks excluded) of 20 euros up to a maximum price of 55 euros. This range includes most Italian restaurants, excluding only fast food and top-level restaurants.

As far as the origin of the raw materials is concerned, the phrasing used was the same as the one adopted in Italy by the Regional Administration of the Veneto, which released the following official claim to certified establishments: 'This restaurant preferentially uses products of regional origin'. This claim fits into the framework of the Italian national regulations that support the use of local products (law no. 3 of 22 January 2010, rules to orient and support the consumption of farm products of regional origin).

Concerning process certifications, the principal certifications available for food products were utilised: organic and GMO-free. These certifications are associated with production processes with different limitations in the use of the production factors. The

Table 1 Choice experiment attributes and levels

\begin{tabular}{ll}
\hline Attributes & Levels \\
\hline Price $(€)$ & $20,25,30,35,40,45,50,55$ \\
Origin & Menu with local products; this restaurant gives preference to products \\
& of regional origin, certified by farmers' associations; no indication \\
Process certifications & $\begin{array}{l}\text { This restaurant uses exclusively organic meats, fruit and vegetables; this } \\
\text { restaurant uses exclusively foods without genetically modified organisms; } \\
\text { no certification }\end{array}$ \\
Service quality and atmosphere & High, medium-high, medium-low \\
\hline
\end{tabular}


phrasings adopted were the following: 'This restaurant uses exclusively organic meats, fruit, and vegetables' and 'This restaurant uses exclusively foods without genetically modified organisms'. Though not specifically regulated, these two claims were utilised, as they are relatively widespread in various restaurants on a voluntary basis. No further information was provided about the meaning of the two certifications.

Finally, three definitions of service quality and atmosphere were considered: high (reasonable wait, refined service and elegant premises), medium-high (occasional long wait, good service and warm atmosphere) and medium-low (long wait, unrefined service and simple premises). These definitions were formulated utilising the description used by Homburg et al. (2005) for levels of satisfaction regarding time, quality of service and characteristics of restaurants.

The choice experiment design was structured considering the four attributes, combined in two unlabelled alternatives plus the no-choice option. The design was obtained by means of Ngene software (ChoiceMetrics Ltd.) utilising a D-optimal orthogonal main effects plan (Street and Burgess 2007). The design thereby obtained provided 12 choice situations.

The model was performed utilising the Latent Gold Choice 4.5 statistical software (Statistical Innovation Inc.). Finally, the segments were profiled by means of Chi-squared Automatic Interaction Detection (CHAID) analysis (Kass 1980). Towards this end, we have used SI-CHAID software, which is integrated with Latent Gold and makes it possible to gather the degree of uncertainty associated with each individual's belonging to a class.

\section{The questionnaire}

The survey opens with a screening question for individuals who have gone to a restaurant at least once a year. The first part of the questionnaire concerns the choice experiment. In order to make the scenario as realistic as possible, the sets of alternatives were represented, drawing inspiration from the way that restaurants are presented on the principal search engines (Fig. 1). Respondents who opted for the non-choice option for more than half of the sets were requested to specify their reasons.

The second part of the questionnaire is intended to investigate the principal motivations not expressly inserted in the choice experiment that underlie the restaurant choice measured using a single-item ('how important is it for you?') and a Likert scale ranging from 1 (not at all important) to 7 (extremely important). The 'Results' section contains the information of the socio-demographic data of the sample; it notes the frequency with which the respondents go to restaurants, as well as their attitude towards the foods from their region, which was measured using a single item ('choosing between different foods, how much would you like a product from your region?') and a Likert scale ranging from 1 (not at all) to 7 (extremely). This part of the questionnaire was introduced with the specific aim of determining the importance attributed to the various dimensions of the local food system and their possible relationship with restaurant preferences. Finally, the fourth part concerns personal values as explanatory factors of restaurant preferences. Values are defined as absolute objectives, which is to say they do not depend on contingent situations that individuals assume as guiding principles in making choices (Schwartz 1992). Schwartz (1992) identifies ten values (universalism, benevolence, conformity, tradition, security, power, achievement, hedonism, stimulation and self-direction) whose effects on behaviour are interpreted by 


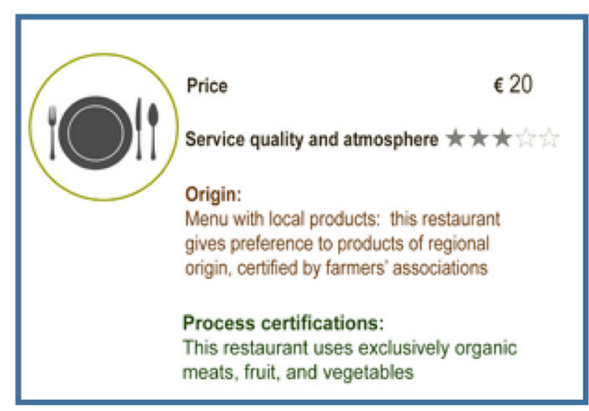

ALTERNATIVE 1

I CHOOSE NONE OF THEM

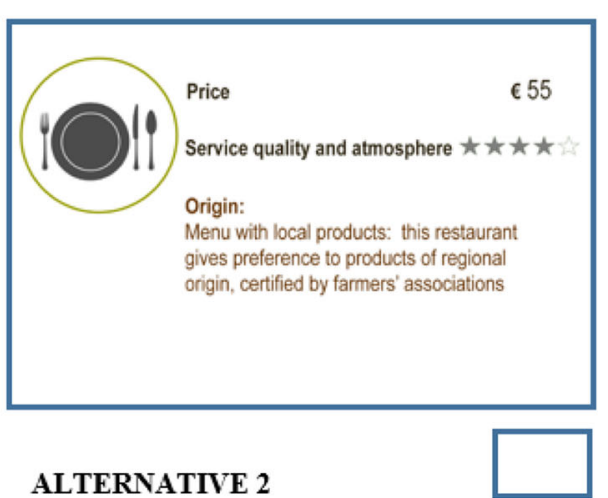

ALTERNATIVE 2

Fig. 1 Example of a set of alternatives shown during the choice experiment

analysing the structure of relationships, or rather, of the priority each value assumes with respect to the others. In fact, the achievement of each value can determine an effect that is congruous or in opposition to the other values. These relationships can be synthesised into two bipolar dimensions represented by self-enhancement versus selftranscendence and by openness to change versus conservation. Self-enhancement expresses power and achievement, while self-transcendence represents universalism and benevolence. On the other hand, openness to change represents values like stimulation and self-direction while, on the contrary, conservation includes tradition, conformity and security. Finally, the hedonism value shares parts of both openness to change and self-enhancement. The values were used to study choice behaviours in reallife situations, showing their effectiveness in interpreting the preference for organic products (Grunert and Juhl 1995), for sustainable food consumption (Thøgersen and Ölander 2002), for fair trade (Doran 2009) and, more in general, for purchasing behaviour (Hansen 2008). The questions were structured utilising the scale developed and tested by Schwartz (2007), which includes verbal portraits of 21 individuals towards whom the respondents are asked to indicate their level of affinity utilising a 7-point scale, from 1 (minimum) to 7 (maximum).

The questionnaires were administered on line by a company (Toluna) specialised in market surveys in the period January-February 2016. Two sub-samples representative for age, gender and education of the countries under study were recruited from the Toluna panel. The sample obtained in this manner does not respond rigorously to the requisites of a random sample. However, bearing in mind the numerousness and the method of selection, we feel it permits a generalisation of results.

\section{Results}

\section{Description of the sample}

The survey concerned a sample made up of 1000 Italian and German individuals who have gone to a restaurant at least once a year and are representative of the population of the two countries with respect to gender, age and education. Table 2 contains a 
description of the sample by all the socio-demographic characteristics surveyed by means of our questionnaire and by the frequency of meals consumed in restaurants.

As far as the motivations behind the choices are concerned, we have evaluated the importance of the elements not included in the choice experiment. Among the restaurant characteristics, the aspects of food quality, such as tastiness and healthiness, prove to be the most important. The preferred information channel for these characteristics is direct experience, while the suggestions of relatives and friends, and specialised guides prove to be much less important (Fig. 2).

Finally, Fig. 3 describes the reasons why the respondents prefer a food from their own region. The data show that the strongest associations concern the freshness of foods and the support of local community.

\section{Results of the choice experiment}

We have performed several models according to different segmentation hypotheses. For each model, the information criteria for the choice of the best specification (Table 3) have been calculated. From the analysis of the information criteria, of the significance and the signs of the estimated parameters, we have selected the model with five classes. The analysis of the model's parameters shows how the consumer's choices are firstly guided by price, though this may assume a very different role among the consumers (Table 4).

In the ambit of the price range considered (20-55 euros per person), the consumers belonging to the first class (27\%) show a positive price coefficient and negative coefficients for all the other attributes. The price attribute proves to be the one with the greatest relative importance (48\%), calculated in relation to the model's coefficients and to the breadth of the attribute's range of variation (Vermunt and Magidson 2005). One interpretation of this result could be that, after choosing the restaurant from within a certain price bracket that for them indicates quality, these consumers associate higher levels of the other attributes with a worsening of quality tied to the information not included in the choice experiment such as taste. In other words, it is as though for a certain price, there was a trade-off between additional claims/certifications and food quality. For this reason, the class has been called 'price driven'.

The second class $(28 \%)$ is made up of individuals whose preferences are oriented around the intermediate price bracket with an average of 28 euros per menu. Price for this cluster still constitutes the most important attribute in restaurant choice (47\%), though in this case, with a negative coefficient. The other attributes instead prove to have a positive impact on choice. The most important among them is the service quality and the atmosphere (27\%), followed by the local origin of the raw materials $(14 \%)$ and process certification (12\%). In particular, with respect to the latter attribute, a preference for organic over GMO-free is observed. The analysis of the willingness to pay (WTP), calculated as an additive inverse of the ratio between the coefficient of the attribute's level and that of the price, has pointed out that this class is willing to pay the highest premium price for the local origin (about 10 euros). This class also presents the highest odds ratio for the 'local' attribute, equal to 2.57, which corresponds to a likelihood of choosing a restaurant with local food certification more than twice as high as to that of a restaurant without this certification. For these reasons, the cluster has been labelled as locavores. 
Table 2 Demographic characteristics and frequency of meals consumed in restaurants of the sample

\begin{tabular}{|c|c|c|}
\hline Country & Freq. & Percent \\
\hline Germany & 500 & 50 \\
\hline Italy & 500 & 50 \\
\hline \multicolumn{3}{|l|}{ Age } \\
\hline $18-24$ & 115 & 12 \\
\hline $25-34$ & 185 & 19 \\
\hline $35-44$ & 215 & 22 \\
\hline $45-54$ & 260 & 26 \\
\hline Over 54 & 225 & 23 \\
\hline \multicolumn{3}{|l|}{ Gender } \\
\hline Female & 505 & 51 \\
\hline Male & 495 & 50 \\
\hline \multicolumn{3}{|l|}{ Level of education } \\
\hline Elementary school & 73 & 7 \\
\hline Secondary school & 623 & 62 \\
\hline University degree and doctorate degree & 304 & 30 \\
\hline \multicolumn{3}{|l|}{ Frequency at restaurants } \\
\hline At least once a week & 198 & 20 \\
\hline More than once a month & 378 & 38 \\
\hline More than once every 3 months & 268 & 27 \\
\hline More than once every 6 months & 86 & 9 \\
\hline More than once a year & 70 & 7 \\
\hline \multicolumn{3}{|l|}{ Number of family members } \\
\hline Single & 160 & 16 \\
\hline Two & 300 & 30 \\
\hline Three & 268 & 27 \\
\hline Four & 201 & 20 \\
\hline More than five & 71 & 7 \\
\hline \multicolumn{3}{|l|}{ Number of children (younger than 12 years old) } \\
\hline None & 697 & 70 \\
\hline One & 207 & 21 \\
\hline Two & 81 & 8 \\
\hline More than two & 15 & 2 \\
\hline \multicolumn{3}{|l|}{ Residence } \\
\hline Capital & 87 & 9 \\
\hline Large city (more than 100,000 inhabitants) & 243 & 24 \\
\hline Urban area $50,000-100,000$ inhabitants & 169 & 17 \\
\hline Urban area 10,000-49,999 inhabitants & 248 & 25 \\
\hline Urban area with fewer than 10,000 inhabitants & 115 & 12 \\
\hline Rural area & 138 & 14 \\
\hline \multicolumn{3}{|l|}{ Family income ${ }^{1}$} \\
\hline Low & 222 & 22 \\
\hline Medium & 395 & 40 \\
\hline Medium-high & 333 & 33 \\
\hline
\end{tabular}


Table 2 Demographic characteristics and frequency of meals consumed in restaurants of the sample (Continued)

\begin{tabular}{lll}
\hline Country & Freq. & Percent \\
\hline Very high & 50 & 5 \\
\hline${ }^{1}$ Low the family income allows me/us to reach the end of the month with great difficulty, medium the family income \\
allows me/us to reach the end of the month well, but without saving anything, medium-high the family income allows \\
me/us to reach the end of the month and to save something, very high the family income allows me/us to reach the end \\
of the month quite easily
\end{tabular}

The third class (17\%) presents a negative price coefficient and is the class for which the importance of this attribute is the maximum (67\%). Coherently, the average price of the menus chosen is the lower price surveyed among the clusters (20 euros). The other attributes all prove to contribute positively to choice; for origin, in particular, a WTP of 2.7 euros is estimated. Given the preference for the lower price brackets, the class has been termed 'savers'.

The fourth class is formed by the 'non-choosers' (24\%). This class, in fact, records an average non-choice rate of about $60 \%$. Analysing the answers on the questionnaire as to the reasons for the non-choice has pointed out the excessively high price as determinant (83\%).

Finally, the fifth class $(4 \%)$ has been labelled 'others'. For this cluster, the parameters are not significant. It is a residual class made up principally of individuals who rarely eat in restaurants, as noted in the third section of the questionnaire (only 18\% eats in restaurants more than once a month). For these reasons, we have not thought it is advisable to consider it in successive analysis.

Investigating the profiles of the four segments has concerned socio-demographic variables, motivations of choice, qualities associated with products of local origin and Schwartz values. Socio-demographic profiling conducted by means of the CHAID method points out significant differences with respect to age $($ LR chi-square $=23.89$, $\mathrm{df}=6 ; p$ value $=0.003$ ) and with respect to the presence of children under 12 (LR chi-square $=13.10, \mathrm{df}=3 ; p$ value $=0.018$ ). In particular, younger people (under 45 years of age) prevail among the locavores and among the price driven, the age bracket between 45 and 54 is the most present among the non-choosers, while the elderly have greater weight among the savers. On the other hand, the presence of children under

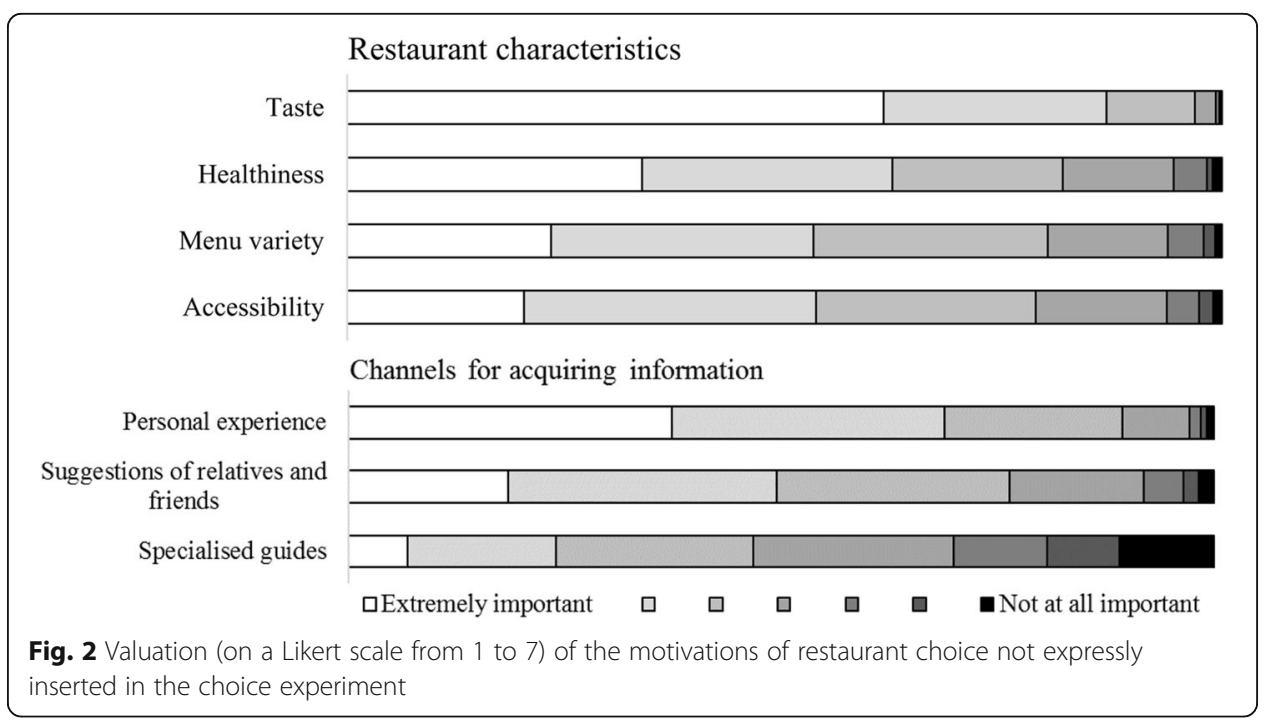




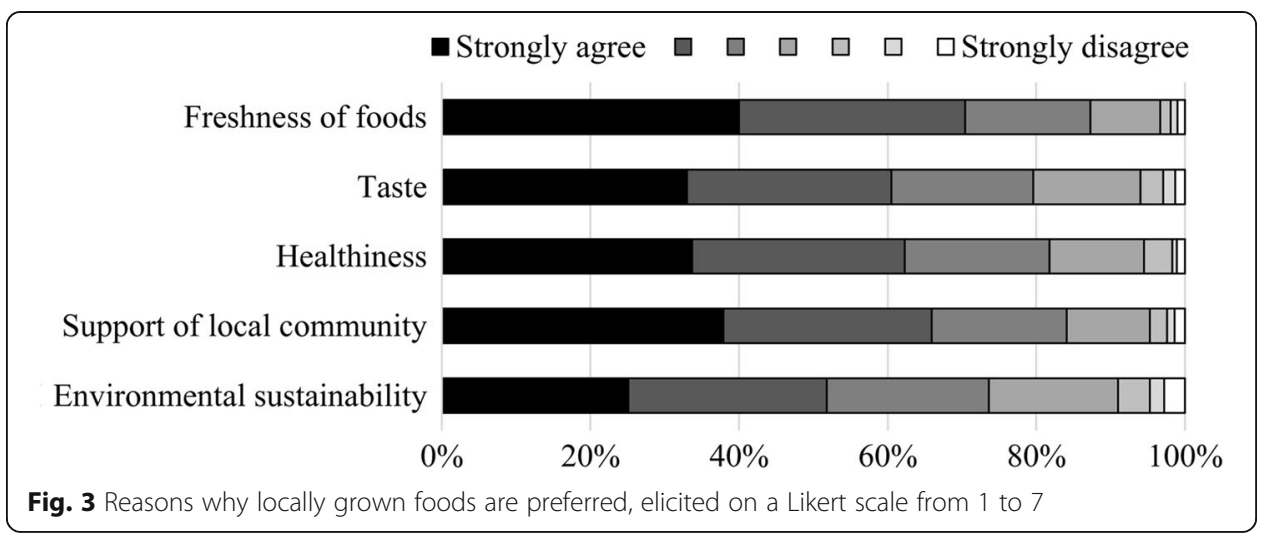

12 years of age proves to be significantly less in the cluster of the savers. The following characteristics, however, did not prove significantly different among the classes: country, residence in urban or rural areas, gender, level of education, profession, family income, number of family members and frequency with which individuals go to restaurants.

As far as the determinants in restaurant choice are concerned, the analysis of the profiles related the motivations not expressly inserted in the choice experiment: taste, healthiness, menu variety and accessibility. Applying the CHAID methodology has shown that for these motivations, no significant differences emerge between the classes, and all the clusters show a pronounced attention for quality in terms of taste and food safety. Significant differences between the classes were also not observed in the channels for acquiring information in order to choose the restaurant.

The survey on the reasons why the respondents state they prefer products from their own region shows significant differences in the characteristics of freshness (LR chi-square $=10.18, \mathrm{df}=3 ; p$ value $=0.040)$ and healthiness $($ LR chi-square $=12.64, \mathrm{df}=3 ; p$ value $=0.032$ ). In particular, the savers class shows a definitely differentiated attitude, indicating levels of importance for these two characteristics lower than the other classes. On the other hand, the locavores differ from the other clusters in their greater association between origin and support to local activities (LR chi-square $=7.72, \mathrm{df}=1$; $p$ value $=0.032$ ). The results in fact show that $43 \%$ of the cluster attributes the maximum importance to this association (score of 7 out of 7 on the Likert scale).

In order to analyse the relationships between consumers' choices and value system, we have applied the principal factor analysis, which has led us to identify four retained factors, considering that for the factors higher than four, the eigenvalues proved negative. In order to facilitate interpretation, we have thus applied an orthogonal rotation of the varimax type (Table 5). The suitability of the analysis was verified using the Kaiser-Meyer-Olkin (KMO) measure. This indicator proved equal to 0.83 and was therefore considered 'meritorious' in literature (Kaiser 1974).

The first factor proves principally correlated to power, achievement, and stimulation. It underlines the dimension of 'self-enhancement and stimulation' and therefore reflects the values of social superiority and self-esteem associated with openness to novelty and change. The second factor presents high values for tradition and conformity and can, therefore, be identified with the dimension of 'conservation', which expresses respect for traditions and the priority of harmony in relations that imply subordinating the self to socially imposed expectations. In the third factor prevails the importance of safety 
Table 3 Latent class information criteria estimation

\begin{tabular}{lllllll}
\hline Model & $\mathrm{LL}$ & $\mathrm{BIC}(\mathrm{LL})$ & $\mathrm{AIC}(\mathrm{LL})$ & $\mathrm{AIC}(\mathrm{LL})$ & $\mathrm{CAIC}(\mathrm{LL})$ & $\mathrm{N}$. par \\
\hline 1-class & $-12,093$ & 24,235 & 24,201 & 24,208 & 24,242 & 7 \\
2-class & $-10,697$ & 21,497 & 21,424 & 21,439 & 21,512 & 15 \\
3-class & -9866 & 19,891 & 19,778 & 19,801 & 19,914 & 23 \\
4-class & -9474 & 19,162 & 19,009 & 19,040 & 19,193 & 31 \\
5-class & -9236 & 18,742 & 18,551 & 18,590 & 18,781 & 39 \\
6-class & -9099 & 18,523 & 18,293 & 18,340 & 18,570 & 47 \\
7-class & -8990 & 18,361 & 18,091 & 18,146 & 18,416 & 55 \\
\hline
\end{tabular}

Note: LL log likelihood, BIC Bayesian information criterion, AIC Akaike information criterion, AIC3 Akaike information criterion 3, CAIC consistent Akaike information criterion, $N$. Par number of parameters

along with social and individual stability (security), along with hedonism, which represents pleasure and one's own gratification of the senses. Finally, the fourth factor is associated with benevolence and universalism and reflects the 'self-transcendence', which is to say the priority of the wellbeing of others with respect to one's own strivings. Scores have been estimated for each respondent and for each of the four factors identified. Table 6 reports the average values for each cluster.

The four clusters were then analysed on the basis of the individual scores achieved for each factor. The price-driven consumers prove to be characterised by selfenhancement and stimulation. The importance for this dimension is shared with the locavores who differ, however, from the previous cluster in their higher conservation. The savers are characterised by a greater importance attributed to the dimension hedonism and security, while the non-choosers combine the priority for hedonism and security and the concern for social welfare (self-transcendence).

Table 4 Latent class model parameters estimation

\begin{tabular}{|c|c|c|c|c|c|}
\hline Attributes & $\begin{array}{l}\text { Cluster } 1 \text { (price } \\
\text { driven) }\end{array}$ & $\begin{array}{l}\text { Cluster } 2 \\
\text { (locavores) }\end{array}$ & $\begin{array}{l}\text { Cluster } 3 \\
\text { (savers) }\end{array}$ & $\begin{array}{l}\text { Cluster } 4 \text { (non- } \\
\text { choosers) }\end{array}$ & $\begin{array}{l}\text { Cluster } 5 \\
\text { (others) }\end{array}$ \\
\hline Price & $0.08^{\mathrm{a}}$ & $-0.09^{\mathrm{a}}$ & $-0.17^{\mathrm{a}}$ & $0.02^{\mathrm{a}}$ & -0.13 \\
\hline \multicolumn{6}{|l|}{ Origin } \\
\hline Local origin & $-0.86^{\mathrm{a}}$ & $0.94^{\mathrm{a}}$ & $0.46^{\mathrm{a}}$ & $-0.57^{\mathrm{a}}$ & 1.91 \\
\hline No Info & 0.00 & 0.00 & 0.00 & 0.00 & 0.00 \\
\hline \multicolumn{6}{|c|}{ Process certifications } \\
\hline Organic & $-0.85^{\mathrm{a}}$ & $0.78^{a}$ & $0.50^{\mathrm{a}}$ & $1.24^{\mathrm{a}}$ & 1.91 \\
\hline GMO-free & $-0.56^{\mathrm{a}}$ & $0.30^{\mathrm{a}}$ & $0.44^{\mathrm{a}}$ & $1.34^{\mathrm{a}}$ & 0.20 \\
\hline No info & 0.00 & 0.00 & 0.00 & 0.00 & 0.00 \\
\hline \multicolumn{6}{|c|}{ Service quality and atmosphere } \\
\hline High & $-1.36^{\mathrm{a}}$ & $1.80^{\mathrm{a}}$ & $1.89^{\mathrm{a}}$ & $1.22^{\mathrm{a}}$ & $1.74^{\mathrm{b}}$ \\
\hline $\begin{array}{l}\text { Medium- } \\
\text { high }\end{array}$ & $-0.76^{a}$ & $1.05^{\mathrm{a}}$ & $1.43^{\mathrm{a}}$ & $-0.46^{\mathrm{a}}$ & -1.40 \\
\hline $\begin{array}{l}\text { Medium- } \\
\text { low }\end{array}$ & 0.00 & 0.00 & 0.00 & 0.00 & 0.00 \\
\hline \multicolumn{6}{|l|}{ Asc } \\
\hline \multirow[t]{2}{*}{ Choice } & $1.09^{\mathrm{a}}$ & $6.39^{\mathrm{a}}$ & $5.82^{\mathrm{a}}$ & $-0.41^{\mathrm{a}}$ & 1.64 \\
\hline & 0.00 & 0.00 & 0.00 & 0.00 & 0.00 \\
\hline
\end{tabular}

${ }^{a}$ Significance is at $1 \%$ level ${ }^{b}$ Significance is at $5 \%$ level 
Table 5 Rotated factor loadings

\begin{tabular}{lllll}
\hline Variable & Factor 1 & Factor 2 & Factor 3 & Factor 4 \\
\hline Power & 0.69 & 0.12 & -0.04 & -0.01 \\
Achievement & 0.65 & 0.22 & 0.28 & 0.10 \\
Edonism & 0.42 & 0.08 & 0.58 & 0.25 \\
Stimulation & 0.65 & 0.04 & 0.27 & 0.32 \\
Self-direction & 0.32 & 0.24 & 0.48 & 0.45 \\
Benevolence & 0.20 & 0.49 & 0.11 & 0.56 \\
Universalism & 0.09 & 0.30 & 0.27 & 0.61 \\
Tradition & 0.15 & 0.63 & 0.12 & 0.24 \\
Conformity & 0.12 & 0.70 & 0.18 & 0.18 \\
Security & 0.04 & 0.39 & 0.56 & 0.14 \\
\hline
\end{tabular}

\section{Discussions and conclusions}

Our study contributes to increasing knowledge in an area to date underexplored, despite the growing 'local' trend and the increase of out of the home consumptions. While for the products consumed in the home, the value of local productions has already been demonstrated (Feldmann and Hamm 2015), the studies conducted in the ambit of restaurants are limited and the findings are still fragmented (Vieregge et al. 2007; Alonso et al. 2013; Lillywhite and Simonsen 2014).

Applying the LC model to analysing the preferences of a representative sample of Italian and German consumers has pointed out an heterogeneous behaviours among consumers. In particular, our findings show the existence of an important market segment (28\%) made up of locavores. We shall focus discussions on this segment, as it is the most interesting for operators who intend to develop an offer that valorises the local origin of products. Locavores indeed have a marked preference for restaurants that use local products, with a likelihood of choosing a restaurant that offers guaranteed local products more than twice as high as that of a restaurant without a certification. Furthermore, they express a willingness to pay a significant premium price for locally grown foods, equal to 10 euros per meal.

The presence of a significant segment of locavores in the ambit of restaurants is coherent with the reports of literature (Lillywhite and Simonsen 2014; Schubert et al. 2010; Vieregge et al. 2007). On the other hand, our results are also compatible with the findings of Alonso et al. (2013) about the limited importance of the local attribute on restaurant choice. Indeed, the differences between our study and that of Alonso et al. (2013) can be attributed to the heterogeneity of preferences. Segmentation has permitted us to focus on the presence of consumers mindful of product origin, which can escape notice when the preferences are analysed as a whole.

Table 6 Average values of the factors for the four clusters analysed

\begin{tabular}{lllll}
\hline Clusters & Self-enhancement and stimulation & Conservation & Edonism and security & Self-transcendence \\
\hline Price driven & 0.10 & 0.04 & -0.01 & 0.01 \\
Locavores & 0.09 & 0.10 & -0.01 & 0.04 \\
Savers & -0.14 & -0.05 & 0.00 & -0.06 \\
No-choosers & -0.08 & -0.06 & 0.06 & 0.05 \\
\hline
\end{tabular}


Profiling the locavores has revealed a general homogeneity of preferences on the territorial level. These consumers are indeed present in similar proportions in both the countries analysed, thus showing how the preference for the local attribute does not differ even between countries with different culinary traditions.

An analysis of the socio-demographic characteristics does not point out particular differences between the clusters except for those related to age. The locavores identify with the younger individuals aged 45 or under. Also, from the viewpoint of motivations for choosing a restaurant that were not included in the choice experiment, there emerged a substantial homogeneity that exalts the importance attributed to the quality of foods, intended as taste and healthiness.

The Schwartz value system proved capable of significantly differentiating the various clusters. In particular, the locavores are represented by individuals with high levels of conservation and self-enhancement and stimulation. While the latter dimension is considered a common denominator of the younger generations (Twenge et al. 2008; Grønhøj and Thøgersen 2009), the more distinctive characteristic consists of the priority that the locavores attribute to respect for customs and tradition, identifying them with people who find gratification in recognising their own cultural identity. They personify the group's solidarity and, with their behaviour, contribute to the survival of their community of reference (Schwartz 2012). This peculiarity is also confirmed by the analysis of the motivations for preferring foods of regional origin, which points out that the locavores attribute a clearly higher importance, compared with the other segments, to the capability of these foods to support local activities.

From the methodological-theoretical viewpoint, the results show that the interest in 'local food' is strongly correlated with the system of values, which can explain the different behaviours surveyed better than the socio-demographic characteristics. This seems to confirm the importance of also considering this type of analysis in studying consumer behaviour.

From the viewpoint of future outlooks, the characteristics of the locavore cluster allow us to foresee a growing attention to local foods and their consumption outside the home. This cluster is in fact made up of young people with a strong aspiration for success and, therefore, with a high probability of forming a group with a growing purchasing power, and capable of influencing the future demand positively. Likewise, their characteristic of being strongly tied to the values of their community seems to be part of a trend of growing interest in local food products, as opposed to the globalisation of consumptions (Bean and Sharp 2011; Rausser et al. 2015). There thus seem to be the conditions to develop a restaurant business characterised by an offer based on local foods, capable of integrating virtuously with regional or sub-regional agricultural productions that specifically target this type of use.

A foodservice characterised by local products can represent an important opportunity for farmers especially in areas with a vocation for tourism. In order for this opportunity to translate into an actual development, at least two conditions must come about. One element that appears essential for this type of development consists in credible guarantees for the consumer.

The other condition concerns the farmers' side and their capability to organise themselves so as to respond to the requirements in terms of reliability, consistency, and constancy of quality levels. In this regard, the coordination among growers for the creation of a 'one-vendor' approach appears to be of strategic importance in order to minimise 
the problems connected with being multiple suppliers and to guarantee conditions of sales convenience and effectiveness.

The main limit of our study is tied to the fact that it is not possible to include in the choice experiment the effects of personal judgement and work-of-mouth judgement concerning one's experience at a restaurant, which literature and our results indicate as potentially important in the choice (Namkung and Jang 2007; Choi and Zhao 2010; Ha and Jang 2010; Ponnam and Balaji 2014). We feel though that our result can represent a correct indication of the existing interest in this attribute for a significant segment of consumers. It does not seem that the quantifications obtained in terms of market quota and WTP can be generalised to all the choice situations, but are instead referable to the cases in which the consumers do not personally know the restaurant and do not possess an external opinion, as in the case of eateries that have recently opened or those that do not have a defined reputation. It is for this restaurant typology that the certification concerning the local origin of products represents an important quality signal, especially if it is accompanied by adequate communication.

Another limit of the study is tied to the hypothetical context of the choice experiment. In order to obtain a greater relevance of results, further developments of the research should foresee analysing the consumer behaviour in the field. In this case, the focus would shift from restaurant choice to menu choice. Other interesting perspectives for further study concern the modalities for realising certification processes of local origin, organising the entire food chain and defining more effective forms of communication.

Authors' contributions

All authors read and approved the final manuscript.

Competing interests

The authors declare that they have no competing interests.

\section{Publisher's Note}

Springer Nature remains neutral with regard to jurisdictional claims in published maps and institutional affiliations.

Received: 23 March 2017 Accepted: 21 October 2017

Published online: 07 November 2017

\section{References}

Alfnes F, Sharma A (2010) Locally produced food in restaurants: are the customers willing to pay a premium and why? Int J Rev Manage 4(3):238-258

Alonso AD, O'Neill M, Liu Y, O'Shea M (2013) Factors driving consumer restaurant choice: an exploratory study from the southeastern United States. J Hospital Mark Manage 22:547-567

Bean M, Sharp JS (2011) Profiling alternative food system supporters: the personal and social basis of local and organic food support. Renew Agric Food Syst 26(3):243-254

Campbell JM, DiPietro RB (2014) Sign of the times: testing consumer response to local food signage within a casual dining restaurant. J Retail Consum Serv 21(5):812-823

Casini L, Contini C, Romano C, Scozzafava G (2015) Trends in food consumptions: what is happening to generation X? $\mathrm{Br}$ Food J 117(2):705-718

Choi J, Zhao J (2010) Factors influencing restaurant selection in South Florida: is health issue one of the factors influencing consumers' behavior when selecting a restaurant? J Foodserv Bus Res 13(3):237-251

Darby K, Batte MT, Ernst S, Roe B (2008) Decomposing local: a conjoint analysis of locally produced foods. Am J Agric Econ 90(2):476-486

Doran CJ (2009) The role of personal values in fair trade consumption. J Bus Ethics 84(4):549-563

Dunne JB, Chambers KJ, Giombolini KJ, Schlegel SA (2011) What does 'local' mean in the grocery store? Multiplicity in food retailers' perspectives on sourcing and marketing local foods. Renew Agric Food Syst 26:46-59

Erraach Y, Gmada SS, Gomez AC, Parra-López CP (2014) Consumer-stated preferences towards protected designation of origin (PDO) labels in a traditional olive-oil-producing country: the case of Spain. New Medit 13(4):11-19

Feenstra GW (1997) Local food systems and sustainable communities. Am J Altern Agric 12:28-36

Feldman C, Murray D, Chavarria S, Zhao H (2015) Menu label accuracy at a university's foodservices. An exploratory recipe nutrition analysis. Appetite 92:24-28

Feldmann C, Hamm U (2015) Consumers' perceptions and preferences for local food: a review. Food Qual Prefer 40:152-164

Frash RE, DiPietro R, Smith W (2015) Pay more for McLocal? Examining motivators for willingness to pay for local food in a chain restaurant setting. J Hospital Mark Manage 24(4):411-434 
Goetzke B, Nitzko S, Spiller A (2014) Consumption of organic and functional food. A matter of well-being and health? Appetite 77:94-103

Gracia A, de Magistris T, Nayga RM (2012) Importance of social influence in consumers' willingness to pay for local food: are there gender differences? Agribusiness 28(3):361-371

Greene WH, Hensher DA (2003) A latent class model for discrete choice analysis: contrasts with mixed logit. Transp Res 37(8):681-698

Grønhøj A, Thøgersen J (2009) Like father, like son? Intergenerational transmission of values, attitudes, and behaviours in the environmental domain. J Environ Psychol 29(4):414-421

Grunert SC, Juhl HJ (1995) Values, environmental attitudes, and buying of organic foods. J Econ Psychol 16(1):39-62

Ha J, Jang SS (2010) Effects of service quality and food quality: the moderating role of atmospherics in an ethnic restaurant segment. Int J Hosp Manag 29(3):520-529

Hansen T (2008) Consumer values, the theory of planned behaviour and online grocery shopping. Int I Consum Stud 32(2):128-137

Homburg C, Hoyer WD, Koschate N (2005) Customers' reactions to price increases: do customer satisfaction and perceived motive fairness matter? J Acad Mark Sci 33(1):36-49

Jung JM, Sydnor S, Lee SK, Almanza B (2015) A conflict of choice: how consumers choose where to go for dinner. Int J Hosp Manag 45:88-98

Kaiser HF (1974) An index of factor simplicity. Psychometrika 39:31-36

Kass GV (1980) An exploratory technique for investigating large quantities of categorical data. Appl Stat 29:119-127

Keeling-Bond J, Thilmany D, Bond C (2009) What influences consumer choice of fresh produce purchase location? J Agric Appl Econ 41(1):61-74

Lillywhite JM, Simonsen JE (2014) Consumer preferences for locally produced food ingredient sourcing in restaurants. J Food Prod Mark 20(3):308-324

Liu PJ, Roberto CA, Liu LJ, Brownell KD (2012) A test of different menu labeling presentations. Appetite 59(3):770-777

Louviere JJ, Woodworth G (1983) Design and analysis of simulated consumer choice or allocation experiments: an approach based on aggregated data. J Mark Res 20:350-367

Lu L, Gursoy D (2016) Would consumers pay more for nongenetically modified menu items? An examination of factors influencing diners' behavioral intentions. J Hospital Market Manage. (In press)

Magidson J, Vermunt JK (2002) Latent class models for clustering: a comparison with K-means. Can J Mark Res 20:37-44

Martinez S, Hand M, Da Pra M, Pollack S, Ralston K, Smith T, Vogel S, Clark S, Lohr L, Low S, Newman C (2010) Local food systems: concepts, impacts, and issues. USDA Economic Research Service, Economic Research Report No. (ERR-97).

McFadden D (1974) Conditional logit analysis of qualitative choice behaviour. In: Zarembka P (ed) Frontiers in econometrics IV. Academic Press, London, pp 105-142

Medeiros CO, Salay E (2013) A review of food senvice selection factors important to the consumer. Food Public Health 3(4):176-190

Menapace L, Raffaelli R (2013) Do 'locally grown' claims influence artisanal food purchase? Evidence from a natural field experiment. In Selected Paper for Presentation at the American Agricultural Economics Association annual meeting, August, 4-6

Namkung Y, Jang S (2007) Does food quality really matter in restaurants? Its impact on customer satisfaction and behavioral intentions. J Hospital Tourism Res 31(3):387-409

Ponnam A, Balaji MS (2014) Matching visitation-motives and restaurant attributes in casual dining restaurants. Int J Hosp Manag 37:47-57

Rausser G, Zilberman D, Kahn G (2015) An alternative paradigm for food production, distribution, and consumption: a noneconomist's perspective. Ann Rev Resour Econ 7(1):309-331

Roininen K, Arvola A, Lähteenmäki L (2006) Exploring consumers' perceptions of local food with two different qualitative techniques: laddering and word association. Food Qual Prefer 17(1):20-30

Schneider ML, Francis CA (2005) Marketing locally produced foods: consumer and farmer opinions in Washington County, Nebraska. Renew Agric Food Syst 20(4):252-260

Schubert F, Kandampully J, Solnet D, Kralj A (2010) Exploring consumer perceptions of green restaurants in the US. Tour Hosp Res 10(4):286-300

Schwartz SH (1992) Universals in the content and structure of values: theoretical advances and empirical tests in 20 countries. Adv Exp Soc Psychol 25(1):1-65

Schwartz SH (2007) Value orientations: measurement, antecedents and consequences across nations. In: Jowell R, Roberts C, Fitzgerald R, Gillian E (eds) Measuring attitudes cross-nationally. Sage Publication, London, pp 161-193

Schwartz SH (2012) An overview of the Schwartz theory of basic values. Online Read Psychol Culture 2(1):1-11

Street DJ, Burgess $L$ (2007) The construction of optimal stated choice experiments: theory and methods (Vol. 647). John Wiley \& Sons, New Jersey

Thøgersen J, Ölander F (2002) Human values and the emergence of a sustainable consumption pattern: a panel study. J Econ Psychol 23(5):605-630

Thorndike AN, Sonnenberg L, Riis J, Barraclough S, Levy DE (2012) A 2-phase labeling and choice architecture intervention to improve healthy food and beverage choices. Am J Public Health 102(3):527-533

Twenge JM, Konrath S, Foster JD, Keith Campbell W, Bushman BJ (2008) Egos inflating over time: a cross-temporal meta-analysis of the narcissistic personality inventory. J Pers 76(4):875-902

Vermunt JK, Magidson J (2002) Latent class cluster analysis. In: Hagenaars JA, McCutcheon AL (eds) Applied latent class analysis (pp. 89-106). Cambridge University Press, Cambridge

Vermunt JK, Magidson J (2005) Latent gold choice 4.0 user's guide. Statistical Innovations, Belmont

Vieregge M, Scanlon N, Huss J (2007) Marketing locally grown food products in globally branded restaurants: do customers care? J Foodserv Bus Res 10(2):67-82

Weber CL, Matthews HS (2008) Food-miles and the relative climate impacts of food choices in the United States. Environ Sci Technol 42(10):3508-3513 